\section{Scaling up iPS cells}

\section{By Joanne Kotz, Senior Editor}

A Memorial Sloan-Kettering Cancer Center team has conducted one of the first large-scale screens of a small molecule library using patientderived induced pluripotent stem cells. ${ }^{1}$ The approach was applied to neuronal cells derived from patients with familial dysautonomia and provides early evidence of its potential for identifying new leads.

Separately, a public-private partnership led by Roche and the University of Oxford is aiming to establish a repository comprising 1,500 induced pluripotent stem (iPS) cells-triplicate samples from 500 patients with diabetes or a wide range of neurological diseases-in an effort to provide a tool for finding new targets and therapeutic leads.

Patient-derived iPS cells are generated by reprogramming skin fibroblasts. These cells can subsequently serve as the starting material for obtaining diseaserelevant cell types through redifferentiation. The goal is to obtain cells from patients that will display phenotypes characteristic of the disease and thus can be used to explore disease mechanisms or screen for small molecules that reverse the disease phenotype.

"For the first time, we have human cells from patients and can differentiate them into different cell types in a dish. If we can identify disease-relevant phenotypes, this has huge potential," said Martin Graf, head of the stem cell platform at Roche.

However, there are many practical challenges in using iPS cells to characterize disease, including identifying strong disease-associated phenotypes and patient-to-patient genetic variations.

For high throughput screening, there is the added need to have a large number of relatively pure cells and an assay that can be scaled up. Because it is difficult to conduct small molecule screens with iPS cells, initial screens to look for compounds that modulate a target or phenotype typically have been conducted with standard, non-patientderived human cell lines.

"The challenge has been getting a population of cells at a sufficient purity and scale that behaves well in plates. There is often a lot of heterogeneity when people try to differentiate iPS cells," said Lorenz Studer, director of the Center for Stem Cell Biology and member of the Developmental Biology Program at Memorial Sloan-Kettering.

In 2009, Studer led a team that generated iPS cells from patients with familial dysautonomia, a rare and fatal peripheral neuropathy caused by a mutation in IKBKAP (inhibitor of $\kappa$-light polypeptide gene enhancer in $B$ cells kinase complex-associated protein) that leads to incorrect gene splicing and reduced protein levels. ${ }^{2}$
When these iPS cells were differentiated into five cell types, IKBKAP expression was lowest in neural crest precursors, which suggested an explanation for the tissue specificity of the disease and provided a disease phenotype for high throughput screening.

Now, Studer's team has screened about 7,000 small molecules to look for compounds that increase expression of IKBKAP in patient-derived neural crest precursors.

Eight hits were further characterized, with all of them boosting $I K B K A P$ expression more potently in neural crest precursors than in the parent iPS cells or in the same iPS cells differentiated into fibroblasts or lymphoblasts. This result suggests it may be important to screen for therapeutic leads in the appropriate genetic disease background and also in the relevant cell type.

One of the top screening hits was the research compound SKF-86466, an adrenergic receptor $\alpha_{2}$ (ADRA2) antagonist.

Results were published in Nature Biotechnology.

"This is an excellent example of why screening in cells from patients can be important," said Stephen Haggarty. "It turns out that none of these compounds significantly increased IKBKAP expression in cells from healthy controls. Finding these hits required the specific genotype relevant to the disease" and benefitted from use of iPS cells that were differentiated to disease-relevant neural crest cells.

Haggarty is an assistant professor of neurology at Harvard Medical School, director of neuropharmacology for the Massachusetts General Hospital psychiatry center for experimental drugs and diagnostics and a senior associate member of the Broad Institute of MIT and Harvard.

Studer told SciBX that his team will now look in more detail at the mechanism of action for some of the other hits from the screen. The researchers also have developed a protocol for making mature neurons to test whether the compounds work in the later neurodegenerative stages of the disease.

\section{BANCC-ing on it}

Separately, a European consortium is betting that patient-specific iPS cells will aid disease understanding and therapeutic discovery in a wide range of neurological diseases-peripheral and central, as well as monogenic and complex.

A public-private partnership dubbed StemBANCC will create a repository of 1,500 iPS cells, comprised of triplicate samples from 500 patients, over the next 5 years.

The partnership was announced in December and is being led by Roche and the University of Oxford. The consortium includes 23 academic institutions, 3 small- and medium-sized enterprises and 10 pharmas. StemBANCC has a 5 -year budget of $€ 55.6$ million (\$72.6 million), which includes $€ 26$ million (\$34 million) from the Innovative Medicines Initiative and $€ 21$ million ( $\$ 27.4$ million) of in-kind contributions from pharma partners.

Graf, who is coordinator for the StemBANCC project at Roche, said 
the pharma has existing academic collaborations around stem cells, for instance one with Harvard Medical School and MGH and another with Boston Children's Hospital. Each of these deals has generated iPS cells from about 20 patients.

"This consortium is something completely different. We are talking about 500 patients. We could hardly undertake such a big project on our own," he said.

StemBANCC will focus on neuropathic pain, neurodegenerative diseases and psychiatric diseases. The project also will generate iPS cells from patients with diabetes.

Zameel Cader, a group leader in the division of clinical neurology at University of Oxford and the academic coordinator of StemBANCC, said the partnership is focusing on neurological diseases because these are "very hard-to-treat conditions where access to relevant tissue is difficult and where pharmas have been turning away."

In addition to banking the iPS cells, the consortium will look for molecular and cellular abnormalities that correlate with disease. "Within each disease we'll stratify and focus on monogenic disorders first to 'cut our teeth' before moving on to more complex disorders," said Cader.

All of the iPS cell lines, along with accompanying profiling data, will be made publicly available over the course of the program.

Cader said that after disease phenotypes are identified, high throughput screens could be run during later stages of the program and will "almost certainly be undertaken principally within pharmas." Any resulting compounds and IP would rest with the project partner, added Graf.

\section{Screen play}

A key unknown is whether sufficiently strong and reproducible phenotypes can be identified for more complex neurological diseases.

Graf said recent work has shown in vitro phenotypes in iPS cellderived neural cells from, for example, patients with schizophrenia or Alzheimer's disease (AD). However, he noted that "if you go into detail, many phenotypes are relatively weak at this stage. We need to have much more robust and reproducible models because we would like to be able to do high throughput screens of more than a million compounds. I am fully convinced in some cases this will be a game changer. In other cases we may not be able to find a robust phenotype."
Studer said finding a compelling phenotype is just one of the major challenges. "We have iPS cell-based models of Parkinson's disease (PD), amyotrophic lateral sclerosis (ALS) and others, but none is ready for a screen," he said. "For PD, there are phenotypes, but they are pretty subtle in my opinion-and on top of that there is heterogeneity and on top of that you need to get to pretty mature neurons to get a phenotype."

"For many disorders like PD, we can't make enough sufficiently pure and large enough quantities of the relevant subtypes of neurons at the moment," agreed Haggerty. "But that is likely going to change very quickly as investigators learn to direct differentiation toward defined lineages using a variety of emerging techniques. The bigger issue will be reproducibility across patients and understanding precise genotypephenotype correlations."

Studer noted a last caveat: "Many neurodegenerative disorders are late onset. How do you model a late-onset disease in a dish? How do you get a cell to behave like an 80 -year-old neuron?"

The results published in Nature Biotechnology have not been patented.

Kotz, J. SciBX 6(1); doi:10.1038/scibx.2013.4

Published online Jan. 10, 2013

\section{REFERENCES}

1. Lee, G. et al. Nat. Biotechnol.; published online Nov. 25, 2012; doi: $10.1038 /$ nbt. 2435

Contact: Lorenz Studer, Sloan-Kettering Institute, Memorial SloanKettering Cancer Center, New York, N.Y.

e-mail: studerl@mskcc.org

Contact: Gabsang Lee, The Johns Hopkins University School of Medicine, Baltimore, Md.

e-mail: glee48@jhmi.edu

2. Lee, G. et al. Nature 461, 402-406 (2009)

\section{COMPANIES AND INSTITUTIONS MENTIONED}

Boston Children's Hospital, Boston, Mass.

Broad Institute of MIT and Harvard, Cambridge, Mass. Harvard Medical School, Boston, Mass.

Innovative Medicines Initiative, Brussels, Belgium

Massachusetts General Hospital, Boston, Mass.

Memorial Sloan-Kettering Cancer Center, New York, N.Y.

Roche (SIX:ROG; OTCQX:RHHBY), Basel, Switzerland University of Oxford, Oxford, U.K. 